\title{
Planning the future exploitation of ornamental stones in Portugal using a weighed multi-dimensional approach
}

\author{
J. Carvalho ${ }^{\mathrm{a}, *}$, C. Lopes ${ }^{\mathrm{b}}$, A. Mateus ${ }^{\mathrm{b}, \mathrm{c}}$, L. Martins ${ }^{\mathrm{d}}$, M. Goulão ${ }^{\mathrm{d}}$

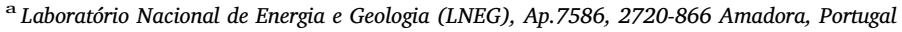 \\ ${ }^{\mathrm{b}}$ Faculdade de Ciências da Universidade de Lisboa, Departamento de Geologia, Ed. C6, Piso 4, Campo Grande, $1749-016$ Lisboa, Portugal \\ ' Instituto Dom Luíz (IDL), Ed. C1, Piso 1, Campo Grande, 1749-016 Lisboa, Portugal \\ ${ }^{\mathrm{d}}$ ASSIMAGRA, Rua Aristides de Sousa Mendes $n^{\circ} 3 B, 1600-412$ Lisboa, Portugal
}

\section{A R T I C L E I N F O}

\section{Keywords:}

Ornamental stones

Portugal

Safeguarding

Land-use planning

Multi-criteria methodology

\begin{abstract}
A B S T R A C T
Portugal is one of the world's leading producers of ornamental stones and, in the last 50 years, this economic sector registered an annual national average growth of $4 \%$. However, the lack of land-use policies that effectively safeguard the access of extractive industry to the places where these resources occur, current and foreseen production is at risk, compromising the contribution of this sector to the national economy and to the supply of forthcoming generations.

The multi-dimensional methodology reported in Mateus et al. (2017) was applied to describe the present-day situation, allowing to objectively identify the tracts hosting ornamental stone resources whose access should be safeguarded, therefore avoiding their sterilisation when confronted to other land-use options. A database on the available geological information concerning 65 ornamental stone tracts, covering $0.43 \%$ of mainland Portugal, was built. Among the 54 active exploitation centres and 11 potential areas (for which there is no production data), only 21 tracts ( $0.07 \%$ of mainland Portugal) were classified as of "public importance", meaning they have an intrinsic value that should by itself support a safeguarding decision on their current and future access. According to the weighed criteria used, several promising tracts were not included in this short group. However, these promising tracts do not overcame the threshold due to the shortage of data about regional exploration surveys or on the resource itself, which reflects difficulties in gathering harmonised geological information for all the listed tracts. Thus, two simulation scenarios were completed, corresponding to an increase in knowledge resulting from regional exploration or local, comprehensive geological studies. As a result of these simulated scenarios, the total number of tracts qualified as of "public importance" increased to $41(0.24 \%$ of mainland Portugal). These results highlight the urgent need to supplement the available geological information, contributing to the establishment of a credible and stable mining plan for the Portuguese ornamental stones sector, thus strengthening its sustainability in the short and long term.
\end{abstract}

\section{Introduction}

The responsible use of endogenous resources, such as those of geological nature, is a critical mainstay of any competitive economic growth committed with short- and long-term roadmaps aiming the "Sustainable Development". Moreover, if this use has been undertaken historically, old practices should be replaced by alternative procedures in line with high demanding environmental and social requirements. In this regard, the access and use of mineral resources are paradigmatic because they still connect traditional and modern approaches to exploit primary raw materials, essential for current and future needs, by investing in new technologies and improved workforce qualifications. As in many other countries, the current and foreseen innovation, competitiveness and internationalisation challenges posed to the Portuguese mining industry are crucial to enhance the desired export growth, either by increasing the ratio Exports/GDP (and/or through adequate replacement of imports by domestic production), or by evolving into more robust added value chains. However, even in presence of evident rise in global market shares supported by innovation and technological improvements, promising paths of future growth can be jeopardised if contemporary public policies do not recognise the need of: (1) assign specific areas to exploitation works, assisting the outset of a correct (and stable) mineral development planning; and (2) safeguard the future access to mineral resources, ensuring the supply of forthcoming

\footnotetext{
* Corresponding author.

E-mail address: jorge.carvalho@lneg.pt (J. Carvalho).
} 